\title{
Sperm Agglutination Measurement
}

National Cancer Institute

\section{Source}

National Cancer Institute. Sperm Agglutination Measurement. NCI Thesaurus. Code

C142290.

The determination of the amount of the motile spermatozoa agg lutination present in a sample. 